\title{
A INFLUÊNCIA DO MARXISMO NA PESQUISA EM EDUCAÇÃO BRASILEIRA
}

\author{
Amarilio Ferreira Jr. ${ }^{1}$ \\ Universidade Federal de São Carlos (UFSCar)
}

\section{RESUMO}

Este artigo tem com objetivo explicitar a importância do significado epistemológico das obras marxianas para as pesquisas desenvolvidas no âmbito do campo educacional brasileiro desde a institucionalização dos Programas de Pós-Graduação, em 1965. O texto está divido em duas partes: na primeira, estabelecemos uma relação entre o processo de produção do conhecimento educacional no contexto da pesquisa realizada nos Programas de Pós-Graduação e a influência das teorias marxistas durante o período de 1970 a 1980. Nessas primeiras décadas, a investigação no campo educacional foi influenciada por duas tendências teórico-metodológicas interpretativas das obras marxianas: o estruturalismo althusseriano e a concepção gramsciniana. Na segunda, sistematizamos a teoria social desenvolvida pro Karl Marx e Friedrich Engels do ponto de vista dos fundamentos teóricometodológicos que são considerados válidos para o processo de investigação dos fenômenos educacionais na contemporaneidade.

Palavras-chave: Marxismo; Pós-Graduação; Pesquisa em Educação.

\section{THE INFLUENCE OF MARXISM IN BRAZILIAN EDUCATION RESEARCH}

\section{ABSTRACT}

This article has the objective to explain the importance of the epistemological meaning of Marxian works for research carried out under the Brazilian educational field since the institutionalization of the Post-Graduation in 1965. The text is divided into two parts: first, we establish a relationship between the process of knowledge production in the context of educational research in the Graduate Programs and the influence of Marxist theories during the period 1970-1980. In these first decades, research in education has been influenced by two theoretical and methodological trends in interpretation of Marxian works: the structuralism Althusserian and the conception Gramscian. In the second, systematized social theory developed pro Karl Marx and Friedrich Engels in terms of theoretical and methodological foundations that are considered valid for the investigation process of educational phenomena in contemporary times.

Keywords: Marxism, Post Graduation, Research in Education.

\section{Introdução}

Este trabalho tem como objeto de estudo a influência epistemológica que o marxismo exerceu no âmbito da pesquisa em educação depois da criação, em 1965, do atual sistema nacional de pós-graduação. A análise em questão tem como fio condutor o seguinte entendimento: o nexo dialético manifesto entre epistemologia e história, ou seja, a produção do conhecimento sempre está sujeita às contingências econômicas, política, sociais e culturais da sua época. No caso específico do campo educacional, a existência dessa relação é insofismável. Pois, os fenômenos educacionais são, em todos os tempos, oriundos das complexas e contraditórias relações sociais que os homens estabelecem entre 
si e a natureza no processo de produção tanto da vida material quanto espiritual. Portanto, as problemáticas de estudo estão sempre vinculadas aos contextos historicamente dados. Por conseguinte, a teoria do conhecimento nada mais é do que uma expressão, no plano da racionalidade lógica, dessa realidade histórica na qual os fenômenos educacionais são forjados. Em outras palavras, os fenômenos engendrados pela sociedade dos homens são sempre portadores das manifestações não só dos elementos objetivos oriundos do reino das necessidades materiais, mas, também, concebidos pela subjetividade desses mesmos homens.

Assim sendo, seguimos a seguinte lógica para abordarmos a influência epistemológica do marxismo no âmbito da pesquisa em educação: o marxismo e a pesquisa em educação no contexto da pós-graduação e o método marxista de investigação e a pesquisa em educação no início século XXI. Na primeira parte, o propósito é explicar a influência que o referencial teórico-metodológico marxista exerceu no contexto das pesquisas em educação depois que a pós-graduação se institucionalizou nas universidades brasileiras e cujo locus acadêmico emblemático foi, na primeira metade dos anos 1970, a Pontifícia Universidade Católica de São Paulo (PUC-SP). O texto realça ainda que, durante a manutenção da sua hegemonia, no período da ditadura militar, o referencial teórico metodológico de investigação marxista se expressou, fundamentalmente, por meio de duas vertentes: o marxismo estruturalista e o marxismo dialético. Já na segunda, a preocupação está centrada na exposição dos principais fundamentos empregados pelo método marxista de pesquisa quando aplicado à investigação dos fenômenos educacionais. Em síntese, o objetivo, aqui, é reafirmar a importância que o marxismo tem para a produção crítica do conhecimento educacional e, ao mesmo tempo, como uma concepção epistemológica que se coloca em contraponto, no âmbito das ciências humanas, aos referenciais pós-modernos de produção dos denominados "saberes educacionais".

\section{O marxismo e a pesquisa em educação no contexto da pós-graduação}

Após 1965, a institucionalização da pesquisa científica, no âmbito acadêmico, ganhou um novo impulso enquanto política de Estado ${ }^{2}$. Portanto, mesmo tendo sufocado o radicalismo intelectual, notadamente de esquerda, as reformas educacionais implementadas pela ditadura militar introduziram elementos de modernização na universidade brasileira. Para a tecnocracia governamental ${ }^{3}$, a pós-graduação teria como objetivo a formação do "capital humano" para dois setores considerados importantes pelos governos militares: as empresas estatais diretamente envolvidas com a modernização das relações capitalistas de produção e as instituições universitárias por meio da qualificação dos seus professores, ou seja, a consolidação de uma comunidade de professores-pesquisadores produtores de novos conhecimentos científicos e, ao mesmo tempo, formadores de quadros dirigentes qualificados para o capitalismo de Estado que executava, de forma acelerada, a última fase da "política de substituição de importações"4. A legislação educacional adotada pelo regime militar instituiu um modelo de pós-graduação que se assemelhava ao norteamericano, isto é, estabelecia programas regulares de ensino e pesquisa para a obtenção dos graus de mestrado e doutorado. A combinação do Parecer n. ${ }^{\text { }}$ 977/65 com os relatórios Atcon (1966) e Meira Mattos (1967) ${ }^{\mathbf{5}}$ forneceram os subsídios da política de pós-graduação contidos na Lei . $^{\circ}$ 5.540/68, que reformou as estruturas da universidade brasileira. A partir de então, a pós-graduação, mestrado e doutorado, passou a ser o locus acadêmico sistemático de realização da pesquisa científica no Brasil.

Especificamente em relação ao campo educacional, assistiu-se a um processo de expansão dos programas de pós-graduação em educação depois da reforma universitária de 
1968, de tal forma que, de 1971 a 1975 foram criados 16 cursos de mestrado e, em 1976, teve início o primeiro de doutoramento. Nesses programas, a produção de estudos e pesquisas educacionais aumentou "em escala e abrangência, concentrando-se, em grande parte, nas dissertações e teses de doutorado defendidas nos diversos cursos, e nos trabalhos de pesquisa de seus professores" (CAMPOS; FÁVERO, 1994, p. 6). Foi neste contexto, da primeira expansão dos cursos de pós-graduação no âmbito da educação, que os fundamentos teóricos e metodológicos derivados do referencial marxista de pesquisa passaram a ser empregados de forma sistemática na investigação dos fenômenos educacionais brasileiros, notadamente naqueles engendrados pelas políticas educacionais adotadas durante a ditadura militar.

O Programa de Pós-Graduação em Filosofia da Educação da PUC-SP, a partir de 1976, pode ser considerado o locus institucional de pesquisa que representara um ponto de inflexão na hegemonia epistemológica que o marxismo alcançou na produção do conhecimento no âmbito da educação ainda em pleno contexto da ditadura militar. Sobre a sua importância para o campo da pesquisa em educação no Brasil, Bernardete Gatti assim se referiu:

(...) a linha de trabalho que deu identidade a esse programa de pósgraduação foi sendo construída como um processo de amadurecimento intelectual coletivo, constituindo-se uma base reflexiva sob a inspiração teórico-metodológica da dialética marxista, especialmente no enfoque desenvolvido nas obras de Gramsci (GATTI, 1994, p. 81).

A partir da experiência desenvolvida pelo Programa de Pós-Graduação em Filosofia da Educação da PUC-SP, sob a liderança acadêmica de Dermeval Saviani ${ }^{6}$, a fundamentação teórico-metodológica derivada da epistemologia marxista passou a ser uma referência orgânica no processo de produção do conhecimento no campo da educação brasileira, principalmente durante o período da ditadura militar. Além disso, há de se destacar também que, ao mesmo tempo em que o marxismo ganhava relevância no Programa de Filosofia da Educação da PUC-SP, ocorria à derrota da luta armada empreendida por organizações de esquerda contra a ditadura militar, o que refletia o recrudescimento da repressão policial-militar sobre a sociedade civil (ALVES, 1985, p. 160 Et seq.). Nesse mesmo contexto, um dos poucos espaços possíveis para a veiculação do marxismo no Brasil passou a ser a própria esfera acadêmica, para onde, inclusive, muitos intelectuais de oposição haviam migrado. Esses quadros, alguns dos quais advindos daquela luta, passaram a atuar como professores e orientadores dos programas de pósgraduação, particularmente na área da educação. Aqui temos, tal como ocorria até o início da década de 1950, o ponto de intersecção entre a militância política marxista e a produção do conhecimento, mas desta vez no campo educacional. Vale ressaltar que a presença desses intelectuais de esquerda na universidade revelava um aspecto antinômico do processo político-educacional da época, pois ao mesmo tempo em que a ditadura pretendia manter o total controle sobre o sistema educacional, não conseguia impedir que no seu interior se desenvolvesse o julgamento mais radical contra a ditadura e o capitalismo: a crítica marxista.

Sobre a influência epistemológica que o marxismo exerceu no campo da pesquisa educacional brasileira, durante as décadas de 1970 e 80, podemos caracterizá-la, grosso modo, por meio da manifestação de duas tendências distintas e complementares. Elas são as seguintes:

$1^{\text {a) }}$ O marxismo estruturalista ${ }^{7}$. Tal abordagem coincide com o período mais repressivo do regime militar e tem como referência teórica os textos de Louis Althusser ou 
as derivações da leitura por ele realizada das obras marxianas. A principal característica dessa tendência foi a tentativa de suprimir a influência que a dialética hegeliana exerceu no processo de formação do pensamento marxista. Para o estruturalismo althusseriano, o marxismo reduzia-se a uma epistemologia científica de interpretação da realidade concreta do mundo, ou seja, era desprovido de qualquer tipo de ideologia ${ }^{8}$. Por via de regra, tal corrente se manifestou, paradoxalmente, quase sempre por meio de uma "ideologia estruturalista" e não mediante a aplicação do método estrutural nos trabalhos de pósgraduação que foram defendidos, principalmente, durante a década de 1970. Nesses primeiros trabalhos, percebe-se uma recusa em investigar a realidade empírica do mundo educacional brasileiro da época, uma vez que a instituição escolar era concebida, pura e simplesmente, como um aparelho reprodutor da ideologia gerada nas entranhas da ditadura militar'. Esses trabalhos de pós-graduação, em geral, preocupavam-se mais em estabelecer o que seria o verdadeiro método científico marxista com base em pesquisas bibliográficas fundamentadas nas obras de Marx, Engels, Lênin, Althusser, Lukács e Gramsci. Produziase, assim, uma espécie de "escolástica marxista" com longas citações e, não raro, com enquadramento da realidade à teoria de forma apriorística.

Outro aspecto relevante que merece nota diz respeito ao sistemático anúncio do referencial teórico nas respectivas introduções ou nos primeiros capítulos dos trabalhos e, paradoxalmente, a ausência da sua aplicação no corpo do trabalho, evidenciando, nesses casos, uma desarticulação entre a teoria anunciada e a abordagem teórico-metodológica utilizada na investigação propriamente dita do objeto. Desse modo, observa-se uma excessiva preocupação por parte dos autores em transcreverem longas citações sobre alguns conceitos da literatura marxista que se converteram em palavras de ordem desprovida de sentido histórico, tais como: "o capital monopolista", "o modo de produção capitalista", "a ideologia burguesa", "a infraestrutura econômica", "a superestrutura jurídica e política", etc. Quanto à educação escolarizada, quase não mereceu a atenção desses pesquisadores já que, pelo prisma althusseriano, ela servia exclusivamente para reproduzir e perpetuar o modo de produção capitalista.

A postura em questão, tal como já foi afirmado, justificava-se pela opção teórica e pelo contexto histórico de então. Pois, a ditadura militar, que exercia uma ideologia tecnicista ${ }^{10}$ e coercitiva sobre a educação, transformou a escola em aparelho ideológico de Estado com o objetivo de reproduzir a natureza autoritária do seu regime político. Assim, a denúncia da ditadura e das contradições do modo capitalista de produção nessas pesquisas são aspectos mais importantes do que o estudo das condições e das contradições da própria realidade educacional brasileira ${ }^{\mathbf{1 1}}$.

$2^{\text {a) }} \mathrm{O}$ marxismo dialético ${ }^{\mathbf{1 2}}$. Essa interpretação corresponde ao processo da transição da ditadura para o Estado de direito democrático e se pautou principalmente pela aplicação do marxismo gramsciano na investigação do fenômeno educativo. As pesquisas deixaram de ser unicamente bibliográficas e passaram a interpretar as problemáticas produzidas pela realidade concreta do mundo educacional brasileiro, já que para Gramsci, a escola não exerce apenas o papel de aparelho reprodutor dos interesses ideológicos de Estado. Ela é considerada, sobretudo, uma instituição superestrutural permeada por contradições sociais, econômicas, políticas e culturais engendradas pelas relações capitalistas de produção e, portanto, constituindo-se num espaço de luta que possibilita a luta contra hegemônico objetivada na perspectiva histórica das classes subalternas. A epistemologia marxista, nessa vertente, foi empregada em larga medida concebendo o materialismo histórico e o materialismo dialético como dois momentos de um mesmo método e não ao contrário, tal como fazia o estruturalismo althusseriano. Portanto, era 
utilizada tanto para se investigar o caráter histórico quanto ideológico dos fenômenos reais da educação brasileira.

As fases acima sintetizadas possibilitam observar duas importantes características: (A) a relativa correspondência entre o período histórico e a aplicação das respectivas epistemologias marxistas. Enquanto o estruturalismo althusseriano foi empregado no período mais autoritário da ditadura militar, relacionado com a estabilidade econômica gerada pelo modelo de modernização acelerada do capitalismo, o marxismo dialético, especialmente na versão gramsciana, foi mais aplicado para se compreender a iniciativa política da sociedade civil contra a manutenção da ordem discricionária imposta pelo regime político que se estabeleceu após o golpe de Estado de 1964; (B) a distinção nos padrões de produção do conhecimento educacional. O emprego da concepção estruturalista gerou um tipo de trabalho de pós-graduação centrada na tentativa de definir qual era o verdadeiro método marxista de investigação - esses trabalhos, geralmente, eram teóricos, isto é, de pesquisa bibliográfica. Já com o marxismo dialético, a pesquisa tomou o sentido da realidade concreta gerada pelo mundo educacional brasileiro e fundamentou os estudos em fontes empíricas que contemplavam tanto o histórico quanto o ideológico do objeto investigado. Em síntese, pode-se considerar, paradoxalmente, que a primeira forma assumiu um caráter mais ideológico do que a segunda ${ }^{\mathbf{1 3}}$.

Em síntese, o marxismo aplicado à pesquisa educacional, seja pelo viés estruturalista ou dialético, foi uma fundamentação teórico-metodológica que exerceu uma forte influência até a derrocada do chamado "socialismo real" (1989-1991). Depois, com o advento e a ascensão preponderante dos referenciais ditos pós-modernos - que se caracterizam, essencialmente, pela perda da relação dialética existente entre o geral (totalidade) e o particular (singularidade) na investigação e interpretação dos fenômenos sociais ${ }^{\mathbf{1 4}}$-, o campo da pesquisa educacional ficou marcado por outro padrão de produção do conhecimento.

\section{O método marxista de investigação e a pesquisa em educação no início século XXI}

A crise ideo-política decorrente do fim do chamado "socialismo real" e, por consequência, o declínio sofrido no campo das ciências humanas, a partir da última década do século passado, não afetaram a essência da teoria social produzida por Marx e Engels durante o século XIX: o método de investigação da realidade historicamente engendrada pela sociedade capitalista. Portanto, apesar de ter ficado reduzido a núcleos residuais de pesquisadores, a utilização do referencial teórico-metodológico marxista continuou perscrutando de forma aguda o mundo fenomênico gerado pela educação brasileira. Assim, a epistemologia marxista na segunda quadra do século XXI, marcada por uma grave crise no sistema capitalista mundial, assume um papel fundamental no processo de produção do conhecimento que explica criticamente as complexas e contraditórias relações existentes entre sociedade e educação. Os fundamentos teórico-metodológicos do referencial marxista de investigação, no âmbito da pesquisa em educação, podem ser sumariados da forma que se segue abaixo:

(A) A hipótese que norteia o processo investigativo é sempre derivada das contradições que se manifestam entre a aparência e a essência do fenômeno. Portanto, ela só pode ser formulada mediante as sucessivas aproximações, por meio de questionamentos que o sujeito da pesquisa processa em relação ao objeto de investigação. Pois, a sua aparência já traz em si alguns elementos da própria essência, principalmente por causa do movimento, interno e externo, inerente ao mundo fenomênico. Portanto, o "jogo de luscofusco" existente entre a essência e a aparência somente pode ser dirimido mediante a 
construção prévia de uma possível explicação sobre a verdade constitutiva daquele determinado fenômeno que está sendo objeto de investigação, ou seja, por meio da construção de uma hipótese que guie, com segurança, o pesquisador a desvelar os "segredos ocultos" pela contradição existente entre a aparência e a essência formativa do fenômeno. Assim, o resultado da investigação seria o processo de exposição lógica portanto, no âmbito da abstração - da essência constitutiva do objeto de pesquisa que estava "oculto" pela aparência.

(B) A investigação científica sempre se processa tomando por base o princípio da relação dialética existente entre o universal, o particular e o singular que compõem a totalidade de uma formação societária historicamente dada. O universal é sempre caracterizado pelas determinações (econômicas, sociais, políticas e culturais) que se repetem no âmago de cada um dos fenômenos particulares. Portanto, cada fenômeno particular traz em si mesmo a unidade e a luta dos contrários que se estabelecem entre a síntese de múltiplas determinações universais e as singularidades que se manifestam apenas no seu interior. É essa luta dos contrários, inerente a cada um dos fenômenos, que produz o princípio da ligação e desenvolvimento universal existente no mundo fenomênico. Assim, podemos dizer que o processo investigativo consiste em separar, no âmbito da abstração lógica, os elementos que formam a síntese das múltiplas características universais e singulares que explicam um determinado fenômeno particular. Por conseguinte, o resultado da pesquisa sempre resulta em uma análise que açambarca o fenômeno particular em duas dimensões complementares: as determinações societárias que o diferencia dos outros fenômenos e, ao mesmo tempo, o conecta com o contexto da totalidade na qual está inserido.

(C) Os fenômenos que se manifestam no "mundo dos homens" estão sempre em constante movimento. Esse movimento é terminado pelas complexas e contraditórias relações que os homens são obrigados a travarem entre si e com a natureza no incessante processo de produção das suas condições materiais e espirituais de existência. Portanto, esses fenômenos engendrados pelas necessidades de sobrevivência dos próprios homens estão constituídos tanto de materialidade como de subjetividade e, por conseguinte, estão submetidos a constantes mudanças. Assim, podemos afirmar que, no âmbito das ciências humanas, os objetos de pesquisa ficam "contaminados" ideologicamente antes mesmo de serem escolhidos pelos pesquisadores, ou seja, eles se inoculam de valores subjetivos durante o próprio processo histórico em que são engendrados. Portanto, o que determina a "cientificidade" da pesquisa na área de ciências humanas e o recorte do objeto de pesquisa com base nos dados empíricos que lhe confere nexos concretos com a realidade societária na qual se encontra situado. E mais, o sujeito da pesquisa não pode definir de forma apriorística o resultado da pesquisa em função da sua opção ideológica relativa à luta de classes produzida pela sociedade capitalista, ou seja, o pesquisador tem que desenvolver o processo investigativo computando a possibilidade de que ele pode chegar a resultados que contrarie as suas próprias convicções ideológicas.

(D) A versão final do relatório da pesquisa nunca se efetiva pelo mesmo caminho do próprio processo investigativo em si, mas, sim, pelos resultados finais alcançados pelo pesquisador. Dito de outra forma: o relatório da pesquisa é simplesmente a síntese das múltiplas determinações econômicas, sociais, políticas e culturais que explicam a consistência material e subjetiva relacionadas à universalidade e à singularidade que configuram o fenômeno particular investigado. Portanto, opera-se uma inversão entre o caminho percorrido durante o processo investigativo e a própria exposição dos resultados atingidos, ou seja, o relatório é simplesmente a síntese final da pesquisa realizada. Assim, o método de investigação fica dissolvido na própria exposição da análise que explica a 
essência constitutiva do objeto investigado. Daí decorre a não necessidade de se elaborar o denominado "primeiro capítulo de apresentação do método"15.

São esses os fundamentos epistemológicos marxistas, acima expostos, que continuamos considerando válidos para o processo de investigação dos fenômenos engendrados pela realidade concreta da educação brasileira e, por conseguinte, para a explicação crítica das suas essências constitutivas.

\section{Conclusão}

Conforme já foi apontado no corpo do texto, houve limites na aplicação do marxismo no âmbito das pesquisas realizadas durante as décadas de 1970 e 80 . Mas, tais limites estavam relacionados, em grande parte, ao contexto político da época e ao estágio em que se encontrava o próprio desenvolvimento da pesquisa educacional no Brasil. Entretanto, se a última quadra do século $\mathrm{XX}$, por um lado, consolidou a pesquisa educacional brasileira; por outro, em decorrência da derrocada da URSS, o marxismo deixou de ser a grande referência epistemológica no campo educacional. Em seu lugar, assumiram proeminência os "novos paradigmas" gerados difusamente pela chamada "pósmodernidade".

De fato, o processo de reestruturação produtiva das relações capitalistas de produção e a ascensão ideológica do neoliberalismo foram os rasgos societários que geraram o declínio da influência epistemológica marxista no campo da pesquisa em educação. Mas, a dialética da história mostrou que a desregulação global do capital financeiro, a chamada "riqueza invisível", prestou-se apenas para aumentar ainda mais a concentração da riqueza material e produzir mais uma cíclica crise econômica que levou à bancarrota muitos dos países centrais do sistema capitalista mundial, já no primeiro decênio do século XXI. Assim, a crise do capitalismo internacional e os fenômenos daí engendrados têm exigido o uso do marxismo como instrumental de análise de valor universal. Uma vez que o objeto de estudo de Marx - a sociedade burguesa - não desapareceu e, portanto, o seu método de investigação continua válido. Talvez isto explique a "redescoberta" do marxismo como epistemologia, especialmente nesta primeira quadra do novo século. Percebemos, enfim, a tendência salutar de se buscar a leitura dos próprios textos marxianos como teoria explicativa dos novos fenômenos sociais e culturais engendrados pelas transformações estruturais que as relações capitalistas de produção sofreram em escala mundial, e especialmente no campo educacional.

\section{Referências}

ALTHUSSER, Louis. A favor de Marx: Pour Marx. $2^{\text {a }}$ Ed. Tradução: Dirceu Lindoso. Rio de Janeiro: Zahar Editores, 1979. 220 p.

ALTHUSSER, Louis. Análise crítica da teoria marxista. Tradução: Dirceu Lindoso. Rio de Janeiro: Zahar Editores, 1967, p. 140 Et seq.;

ALTHUSSER, Louis. Sobre a relação de Marx com Hegel. In: D'HONDT; DERRIDA; ALTHUSSER et al. Hegel e o pensamento moderno. Porto: Rés Editora, 1979. p. 110 Et seq.;

ALTHUSSER, Louis. O marxismo não é um historicismo. In: et al. Ler $\boldsymbol{O}$ Capital. Tradução: Nathanael C. Caixeiro. Rio de Janeiro: Zahar Editores, 1980. v. II, p. 65 Et seq. 
ALTHUSSER, Louis. Aparelhos ideológicos de Estado: notas sobre os Aparelhos Ideológicos de Estado. Tradução: Walter José Evangelista et al. $4^{\text {a }}$ Ed. Rio de Janeiro: Edições Graal, 1989. p. 66 Et seq.

ALVES, Maria Helena Moreira. Estado e oposição no Brasil (1964-1984). $3^{\text {a }}$ ed. Tradução: Clóvis Marques. Petrópolis: Vozes, 1985. 337 p.

ASSOCIAÇÃO DE DOCENTES DA UNIVERSIDADE DE SÃO PAULO. Livro negro da USP: o controle ideológico na universidade. São Paulo: ADUSP, 1978.

BALLET, René et al. Estruturalismo e marxismo. Tradução: Carlos Henrique de Escobar. Rio de Janeiro: Zahar Editores, 1968. 289 p.

BITTAR, Marisa; FERREIRA Jr., Amarilio. História, epistemologia marxista e pesquisa educacional brasileira. Educação \& Sociedade, Campinas, v. 30, n. 107, p. 489-511, maio/ago. 2099.

CAMPOS, Maria Malta; FÁVERO, Osmar. A pesquisa em educação no Brasil. Cadernos de Pesquisa, São Paulo, n. ${ }^{\circ}$ 88, p. 5-17, fev. 1994.

CARDOSO, Miriam Limoeiro. A ideologia como problema teórico. In: Ideologia do desenvolvimento Brasil: JK-JQ. $2^{\text {a }}$ Ed. Rio de Janeiro: Paz e Terra, 1978. p. 39-84.

COUTINHO, Carlos Nelson. O estruturalismo e a miséria da razão. Rio de Janeiro: Paz e Terra, 1972. p. 224 p.

ENGELS, Friedrich. Anti-Dühring: filosofia, economia política, socialismo. 2. ed. Rio de Janeiro: Paz e Terra, 1979.

ENGELS, Friedrich. Carta a Conrad Schmidt, 27 de outubro de 1890. In: MARX e ENGELS. Obras escolhidas em três tomos. Tradução: José Barata-Moura et al. LisboaMoscovo: Editorial “Avanti!”-Edições Progresso, 1985. p. 549-556.

FERREIRA Jr., Amarilio; BITTAR, Marisa. O marxismo como referencial teórico nas dissertações de mestrado em Educação da UFSCar (1976-1993). Cadernos CEMARX, Campinas, v. 1, n. 2, p. 65-71, 2005.

FERREIRA Jr., Amarilio; BITTAR, Marisa. Jarbas Passarinho, ideologia tecnocrática e ditadura militar. Revista HISTEDBR On-line, Campinas, n. 23, p. 3 -25, set. 2006.

FERREIRA Jr., Amarilio; BITTAR, Marisa. Educação e ideologia tecnocrática na ditadura militar. Cadernos CEDES, Campinas, v. 28, n. 76, p. 333-355, set./dez., 2008.

FERREIRA Jr., Amarilio. História da educação brasileira: da Colônia ao século XX. São Carlos: EdUFSCar, 2010.

GAMBOA, Silvio Ancizar Sanchez. A dialética na pesquisa em educação: elementos de contexto. In: FAZENDA, Ivani (Org.). Metodologia da pesquisa educacional. São Paulo: Cortez, 1989. p. 91-115.

GATTI, Bernardete A. O doutorado em educação da PUC-SP e o mestrado em educação da UFSCar. In: SEVERINO, Antônio Joaquim et al. Dermeval Saviani e a educação brasileira: o simpósio de Marília. São Paulo: Cortez, 1994. p. 77-85.

GRAMSCI, Antonio. Introdução ao estudo da filosofia. A filosofia de Benedetto Croce. In:

. Cadernos do cárcere. Tradução: Carlos Nelson Coutinho. Rio de Janeiro: Civilização Brasileira, 1999. 494 p. v. 1.

GRAMSCI, Antonio. Os intelectuais. O princípio educativo. In: Cadernos do cárcere. Tradução: Carlos Nelson Coutinho. Rio de Janeiro: Civilização Brasileira, 2000. p. 11-192. v. 2. 
MARX, Karl. Manuscritos econômico-filosóficos. Tradução de Jesus Ranieri. São Paulo: Boitempo Editorial, 2004.

MARX, Karl. Método da economia política. In: Contribuição para a crítica da economia política. Tradução de Maria Helena Barreiro Alves. Lisboa: Editorial Estampa, 1971. p. 228-237.

MARX, Karl. Prefácio. In: Contribuição para a crítica da economia política. Tradução de Maria Helena Barreiro Alves. Lisboa: Editorial Estampa, 1971. p. $27-31$.

MARX, Karl; ENGELS, Friedrich. Feuerbach. In: A ideologia alemã. 4. ed. Tradução de Conceição Jardim et al. Portugal: Editorial Presença; Brasil: Livraria Martins Fontes, 1980. v. I, p. 11-102.

MARX, Karl; ENGELS, Friedrich. Manifesto do Partido Comunista. In: Obras escolhidas em três tomos. Tradução de Álvaro Pina. Lisboa: Edições "Avante!”; Moscovo: Edições Progresso, 1982. p. 93-136.

MARX, Karl. A miséria da filosofia. Tradução: José Paulo Netto. São Paulo: Global, 1985. $225 \mathrm{p}$.

MATTOS, Meira. Relatório Meira Mattos, Revista Paz e Terra, Rio de Janeiro, n. 9, p. 199-241, 1969.

PRADO Jr., Caio. O marxismo de Louis Althusser. In: Estruturalismo de LeviStrauss. Marxismo de Louis Althusser. São Paulo: Editora Brasiliense, 1971. p. 71-108.

TAVARES, Maria da Conceição. Auge e declínio do processo de substituição de importações no Brasil. In: _. Da substituição de importações ao capitalismo financeiro. $6^{\text {a }}$ ed. Rio de Janeiro: Zahar, 1977. p. 29-124.

\footnotetext{
Notas:

${ }^{1}$ Doutor em História Social pela Universidade de São Paulo (USP), professor do Departamento de Educação da Universidade Federal de são Carlos (USP) e pesquisador PQ do CNPq.

${ }^{2} \mathrm{~A}$ institucionalização formal da pós-graduação se efetivou por meio do Parecer n. 977 do Conselho Federal de Educação, de autoria do conselheiro Newton Sucupira e aprovado em dezembro de 1965.

${ }^{3}$ Em relação ao papel desempenhado pela tecnocracia estatal, durante a ditadura militar, no campo educacional: conferir: FERREIRA Jr.; BITTAR, 2008, p. 334 Et seq.

${ }^{4}$ A respeito da "política de substituição das importações", digo de nota é: TAVARES, 1977, p. 29-124.

${ }^{5}$ Sobre a política de estruturação da pós-graduação no Brasil contida no Relatório Meira Mattos, consultar: MATTOS, 1969, p. 223 Et seq.

${ }^{6}$ Sobre a influência do marxismo no Programa de Pós-Graduação em Filosofia da Educação da PUC-SP, Dermeval Saviani afirmou o seguinte: "progressivamente fui introduzindo também algumas precisões no interior das concepções de Filosofia da Educação distinguindo, por exemplo, na concepção humanista tradicional a vertente leiga e a religiosa, distinguindo na concepção humanista moderna a pedagogia nova e as pedagogias não-diretivas, e assim por diante. E também, à medida que a experiência do curso foi se desenvolvendo, o esquema das principais concepções acabou se configurando com cinco grandes tendências no lugar das quatro anteriores. Introduzi a concepção crítico-reprodutivista porque pareceu importante que ela não fosse confundida com a perspectiva dialética propriamente dita. Dados também os diferentes entendimentos que conduziam a certas ambiguidades em relação à expressão 'concepção dialética' passei, a partir do $2^{\circ}$ semestre de 1984, a dar preferência à denominação 'histórico-crítica' " (apud GATTI, 1994, p. 80-81).

${ }^{7}$ Para uma ampla compreensão do marxismo estruturalista, conferir: BALLET, et al., 1968, p. 289.

${ }^{8}$ A respeito do significado negativo da dialética hegeliana no pensamento de Marx, verificar: ALTHUSSER, 1967, p. 140 Et seq.; ALTHUSSER, 1979. p. 110 Et seq.; ALTHUSSER, 1980. v. II, p. 65 Et seq.

${ }^{9}$ Em relação ao conceito de "aparelho ideológico de Estado", cotejar: ALTHUSSER, 1989. p. 66 Et seq.
} 


\footnotetext{
${ }^{10} \mathrm{~A}$ respeito da ideologia tecnicista que plasmou a educação brasileira durante a ditadura militar, conferir: FERREIRA Jr., BITTAR, 2008, p. 341 Et seq.

${ }^{11}$ Três textos críticos em relação ao marxismo althusseriano, produzidos no Brasil, são dignos de nota: CARDOSO, 1978, p. 39-84; PRADO Jr., 1971, p. 71-108; COUTINHO, 1972, p. 224 p.

${ }^{12}$ Sobre a importância da dialética hegeliana no pensamento de Marx, consultar: MARX, 1977, p. 276-278; ENGELS, 1985, p. 549-556; GRAMSCI, 1999, v. I, p. 275 Et seq.

${ }^{13}$ As definições de "marxismo estruturalista" e "marxismo dialético" encontradas no corpo do texto são transcrições com pequenas adaptações de: FERREIRA Jr., BITTAR, 2005, p. 68-70.

${ }^{14}$ Sobre as divergências existentes entre a epistemologia marxista e as concepções pós-modernas no processo de produção do conhecimento educacional, consultar: BITTAR; FERREIRA Jr., 2009, p. 492 Et seq.

${ }^{15}$ Todas as referências aos princípios, leis e categorias concernentes ao método marxista de investigação utilizadas nesta parte do texto encontram-se em: ENGELS, Friedrich. Anti-Dühring, p. 81 et seq.; MARX, Karl. Prefácio, p. 27; MARX, Karl. Método da economia política, p. 228 et seq; MARX, Karl. Manuscritos econômico-filosóficos, p. 115 et seq; MARX, Karl; ENGELS, Friedrich. Feuerbach, p. 29 et seq.; MARX, Karl; ENGELS, Friedrich. Manifesto do Partido Comunista, p. 107 et seq.
}

Recebido:Fevereiro-2013

Aprovado: Março-2013 